\title{
Tropical cyclones over the Arabian Sea and Bay of Bengal tracked by Megha-Tropiques SAPHIR during 2011-2018
}

\author{
M P VASUdhA* (1) and G RAJU \\ Department of Electronics and Communication Engineering, School of Engineering and Technology, Jain \\ (Deemed-to-be University), Bangalore, India. \\ *Corresponding author. e-mail: mp.vasudha@gmail.com
}

MS received 10 August 2017; revised 25 June 2018; accepted 13 October 2018; published online 28 March 2019

Monitoring of tropical cyclones (TCs) using the Sondeur Atmosphérique du Profil d'Humidité Intertropicale par Radiométrie (SAPHIR) sounder on-board the Megha-Tropiques satellite is attempted on a qualitative basis. The sounder with a high resolution of $10 \mathrm{~km}$ at nadir, combined with its high temporal observation ability, 4-6 times a day, and with six channels at $183.31 \pm 11.0 \mathrm{GHz}$, is used for tracking the cyclones. The study has been performed by applying SAPHIR brightness temperature datasets to the cyclonic regions. In this study, 25 TCs from 2011 to 2018 in the Arabian Sea and the Bay of Bengal over the North Indian Ocean have been observed. A comparison of six channels of SAPHIR shows the clear variations of the eye of the cyclone under various conditions. Furthermore, the positional variations obtained by multiple linear regression models are used to observe the evolution of the cyclone storm from its genesis to dissipation/landfall for all the 25 cyclones. The location accuracy is found to be $0.2-0.3^{\circ}$, as observed from the SAPHIR dataset that agrees reasonably well with the India Meteorological Department dataset and Advanced Microwave Sounding Unit sounder dataset in cyclone tracking. This study attempts at using the unique features of high temporal resolution, good spatial resolution and more channels and is expected to complement other methods of cyclone tracking.

Keywords. Brightness temperature; sounder channels; cyclone; tracking; SAPHIR; Megha-Tropiques.

\section{Introduction}

Tropical cyclone (TC) is generally explained as a rapidly rotating cloud system with a central lowpressure area over tropical regions associated with closed low-level atmospheric circulation, strong wind and concentric cycles of cloud arrangement of thunderstorms. Owing to the limitations associated with making in situ observations over the sea surface during the storm period, researchers and scientists are using satellite data to study and understand the life cycle of TCs. It is observed that $\sim 5$ to $6 \%$ of the TCs around the world are formed in the Arabian Sea (ARB) and Bay of Bengal (BOB) basins of the North Indian Ocean (NIO) (Maneesha and Manasa Ranjan 2015). Passive microwave sensors have been extensively used for oceanographic applications for the past four decades (SEASAT, SSMI, MHS, HSB, AMSU-A \& B and SAPHIR) (Ulaby et al. 1986; Demuth et al. 2004; Moore and Jones 2004). While observing severe storms and features of TC life cycle, the microwave sounder can sense microwave radiation through the cloud-covered areas without much atmospheric attenuations. The visible or infrared sensors cannot sense microwave radiation through 
clouds. Hence, compared to microwave sounders, observations from microwave visible or infrared sensors are subject to more atmospheric attenuations.

Space-borne microwave radiometer observation plays a pivotal role in the early detection of TC life cycle beginning from cyclone genesis, its growth followed by land fall and/or weakening into a lowpressure area. The formation of eye of the TC is associated with the genesis and beginning of rapid intensification. TC characteristics such as position or location, eye centre fix, central pressure, pressure depth and direction of movement are used for detecting TC genesis, eye centre and eyewall replacement that are used for estimating TC intensity (Velden et al. 2007). Roy Bhowmik (2003) used the genesis parameter to study the developing and non-developing systems over the NIO and observed parameter values $\sim 20 \times 10^{-12} \mathrm{~s}^{-2}$ against the tropical number (T-No) 1.5. The visible and infrared imageries from the meteorological satellite to estimate the eye of the cyclone centre can be used only during clear sky conditions. On the other hand, by using the microwave image, we can simulate radiances to locate the band and eye pattern both under clear and cloudy sky conditions. Demuth et al. (2004) showed that the estimation of eye of the TC size and intensity is also possible using warm core brightness temperature data at $250 \mathrm{mb}$ level obtained from the Advanced Microwave Sounding Unit (AMSU) Sounder with CF of $54.96 \mathrm{GHz}$. Velden et al. (2007) developed a technique, generally known as Dvorak technique, for determining the TC centre location/TC intensity by utilising kinematic organisational patterns of clouds structure. Nishimura et al. (2008) used the microwave imagery from AMSR-E sensor aboard earth observing satellite to analyse the inner structures of eye of the cyclone pattern and estimate the positions of the eye of the cyclone centre using the Dvorak method. Kotal and Roy Bhowmik 2011 proposed the multi-model ensemble (MME) technique, which depends on the multiple linear regression-based minimisation principle to forecast positions with respect to observed latitude and longitude position of cyclones over the North Indian Sea. We applied the three selected predictors from numerical weather prediction model at 12-h interval up to $120 \mathrm{~h}$ in the MME technique for forecasting and tracking the present cyclone in real-time.

Sondeur Atmosphérique du Profil d'Humidité Intertropicale par Radiométrie (SAPHIR) on board Megha-Tropiques (MT) satellite has a good spatial resolution of $10-20 \mathrm{~km}$ and a large swath of $\sim 2060$ $\mathrm{km}$. MT was launched in a near-circular inclined orbit of $20^{\circ}$ on 12 October 2011 (Raju 2012) and gives high-quality information on ocean surface (Aguttes et al. 2000), atmospheric humidity profile (Balaji et al. 2014) and land-related application (Suresh Raju et al. 2013). Observation of patterns and features of the cloud of low-pressure area of TC system over ARB and BOB by microwave sounder instrument aboard satellites is becoming increasingly important. It is with encouraging possibility that the SAPHIR sounder data were attempted to be used to explain the observed intensity and structure changes in TCs. Sivira et al. (2015) proposed that measurements of SAPHIR sounder can be used to retrieve six-layer relative humidity $(\mathrm{RH})$ profiles. This study observed that by utilising SAPHIR sounder Level 1A dataset, it is conceivable to get cloud-top brightness temperatures (normally in the eye) from all the six channels based on various frequency channels (i.e., $183.31 \pm 11.0 \mathrm{GHz})$ in cyclone area at near realtime perceptions. Furthermore, repeated use of the sensor around 4-6 times each day is valuable in

Table 1. Tropical cyclones formed over Arabian Sea (2011-2018).

\begin{tabular}{|c|c|c|c|c|c|c|c|}
\hline Year & Name & Formed & $\begin{array}{l}\text { Time } \\
\text { (UTC) }\end{array}$ & $\begin{array}{l}\text { Latitude } \\
\qquad\left({ }^{\circ} \mathrm{N}\right)\end{array}$ & $\begin{array}{l}\text { Longitude } \\
\qquad\left({ }^{\circ} \mathrm{E}\right)\end{array}$ & Dissipated & $\begin{array}{c}\text { Duration } \\
\text { (h) }\end{array}$ \\
\hline 2011 & Keila & 29 October 2011 & 06.00 & 13.0 & 62.0 & 04 November 2011 & 141 \\
\hline 2012 & Murjan & 23 October 2012 & 03.00 & 11.0 & 65.5 & 26 October 2012 & 87 \\
\hline 2014 & Nanauk & 10 June 2014 & 09.00 & 15.5 & 68.5 & 14 June 2014 & 99 \\
\hline 2014 & Nilofar & 25 October 2014 & 00.00 & 12.5 & 61.5 & 31 October 2014 & 144 \\
\hline 2015 & Ashobaa & 07 June 2015 & 03.00 & 14.5 & 68.5 & 12 June 2015 & 120 \\
\hline 2015 & Chapala & 28 October 2015 & 03.00 & 11.5 & 65.0 & 04 November 2015 & 168 \\
\hline 2015 & Megha & 05 November 2015 & 00.00 & 14.1 & 66.0 & 10 November 2015 & 126 \\
\hline 2018 & Sagar & 16 May 2018 & 18.00 & 13.2 & 49.5 & 20 May 2018 & 96 \\
\hline 2018 & Mekunu & 21 May 2018 & 12.00 & 09.1 & 57.3 & 27 May 2018 & 168 \\
\hline
\end{tabular}


Table 2. Tropical cyclones formed over Bay of Bengal [2011-2018].

\begin{tabular}{|c|c|c|c|c|c|c|c|}
\hline Year & Name & Formed & $\begin{array}{l}\text { Time } \\
\text { (UTC) }\end{array}$ & $\begin{array}{l}\text { Latitude } \\
\qquad\left({ }^{\circ} \mathrm{N}\right)\end{array}$ & $\begin{array}{l}\text { Longitude } \\
\quad\left({ }^{\circ} \mathrm{E}\right)\end{array}$ & Dissipated & $\begin{array}{c}\text { Duration } \\
(\mathrm{h})\end{array}$ \\
\hline 2011 & Thane & 25 December 2011 & 12.00 & 08.5 & 88.5 & 31 December 2011 & 159 \\
\hline 2012 & Nilam & 28 October 2012 & 06.00 & 09.5 & 86.0 & 01 November 2012 & 78 \\
\hline 2013 & Viyaru & 10 May 2013 & 09.00 & 05.0 & 92.0 & 17 May 2013 & 87 \\
\hline 2013 & Phailin & 08 October 2013 & 03.00 & 12.0 & 96.0 & 14 October 2013 & 144 \\
\hline 2013 & Helen & 19 November 2013 & 00.00 & 10.0 & 84.0 & 23 November 2013 & 81 \\
\hline 2013 & Lehar & 23 November 2013 & 12.00 & 08.5 & 96.5 & 28 November 2013 & 117 \\
\hline 2013 & Madi & 06 December 2013 & 12.00 & 10.0 & 84.0 & 13 December 2013 & 168 \\
\hline 2014 & Hudhud & 07 October 2014 & 03.00 & 11.5 & 95.0 & 14 October 2014 & 144 \\
\hline 2015 & Komen & 26 July 2015 & 03.00 & 22.0 & 90.8 & 02 August 2015 & 114 \\
\hline 2016 & Roanu & 17 May 2016 & 03.00 & 11.0 & 81.0 & 23 May 2016 & 110 \\
\hline 2016 & Kyant & 21 October 2016 & 03.00 & 17.0 & 91.2 & 28 October 2016 & 141 \\
\hline 2016 & Nada & 29 November 2016 & 12.00 & 10.7 & 80.7 & 02 December 2016 & 57 \\
\hline 2016 & Vardah & 07 December 2016 & 00.00 & 11.2 & 90.5 & 13 December 2016 & 150 \\
\hline 2017 & Maarutha & 15 April 2017 & 03.00 & 12.0 & 88.0 & 17 April 2017 & 48 \\
\hline 2017 & Mora & 28 May 2017 & 03.00 & 14.5 & 89.5 & 31 May 2017 & 078 \\
\hline 2017 & Ockhi & 29 November 2017 & 18.00 & 06.6 & 78.8 & 06 December 2017 & 162 \\
\hline
\end{tabular}

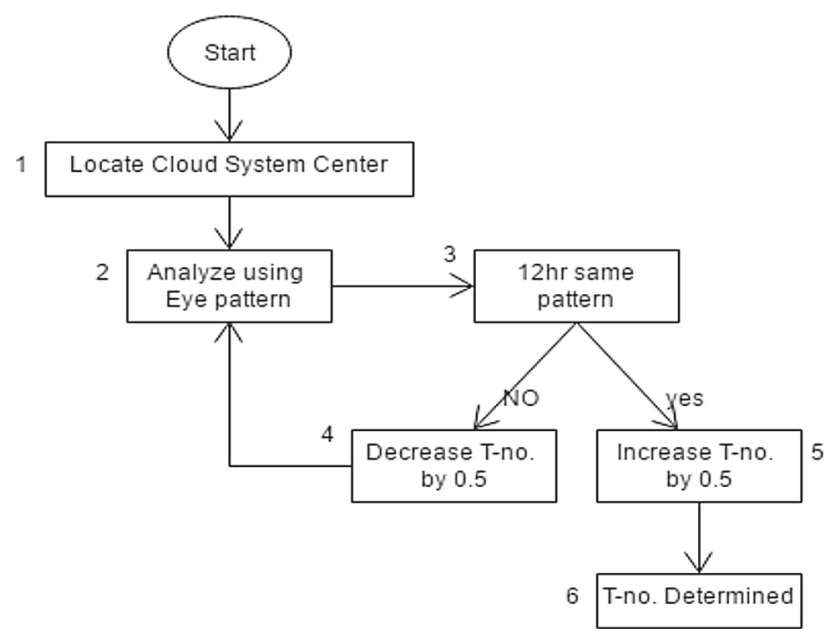

Figure 1. Procedure for T-number determination.

determining the features of the eye of the cyclone region and also in locating and classifying the cyclone and recognising the eye pattern of the cyclone.

\section{Data source}

The SAPHIR sounder brightness temperature data (Level 1) have been used to measure the microwave radiation emitted through the top of water clouds of tropical cyclonic region over $\mathrm{ARB}$ and $\mathrm{BOB}$ basins of NIO. The SAPHIR metadata product named as 'MT1SAPSL1A' (Megha-Tropiques SAPHIR Segment-wise Level 1A) from 2011 to

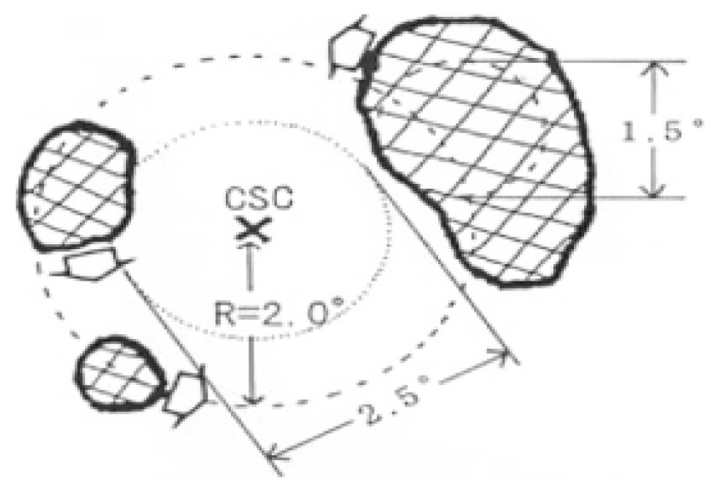

Figure 2. Cloud analysed for T-number (Velden et al. 2006).

2018 contains all the parameters of brightness temperature and humidity profile measured for all the data of six channels in HDF file format by Meteorological and Oceanographic Satellite Data Archival Centre (MOSDAC ISRO, Ahmedabad) (www.mosdac.gov.in) and ICARE data processing centre (France; www.icare.fr). SAPHIR Level 1 (L1) data products from all channels in scan mode are available in different formats such as L1A, L1A2 and L1A3. L1A data provide brightness temperature data product, merged with time and location information (Vasudha and Raju 2017, 2018). They also include segment-wise data (possibly exceeding one revolution, variable in size) and orbit-wise data (i.e., one revolution) (Karouche and Raju 2013). In our analysis, L1A segment-wise brightness temperature data products (from genesis to dissipation) obtained from all six channels 


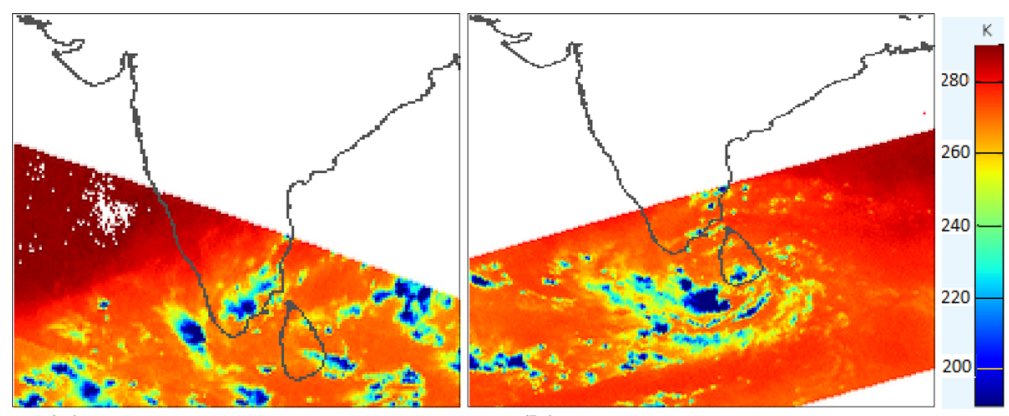

(a) 28-11-2017 (T0.5 \& 142.48 K)

(b) $29-11-2017$ (T1.5 \& $124.68 \mathrm{~K})$

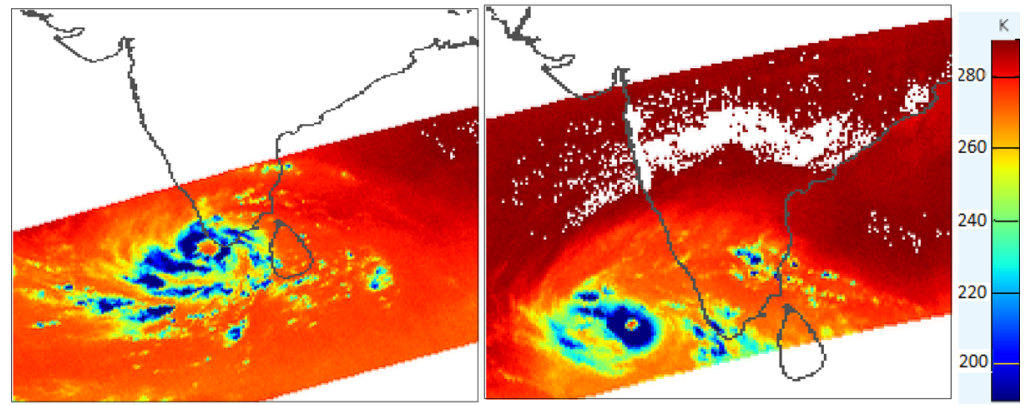

(c) $30-11-2017$ (T2.5 \& $119 \mathrm{~K})$

(d) $01-12-2017$ (T3 \& 112.3 K)

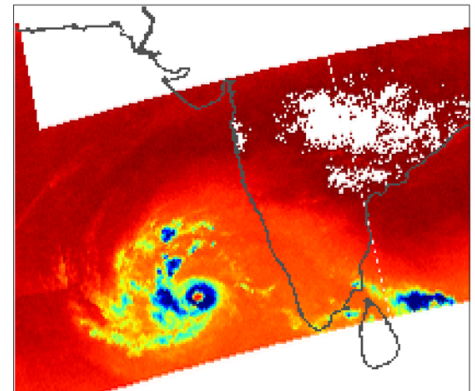

(e) $02-12-2017(\mathrm{~T} 4 \& 106.3 \mathrm{~K})$

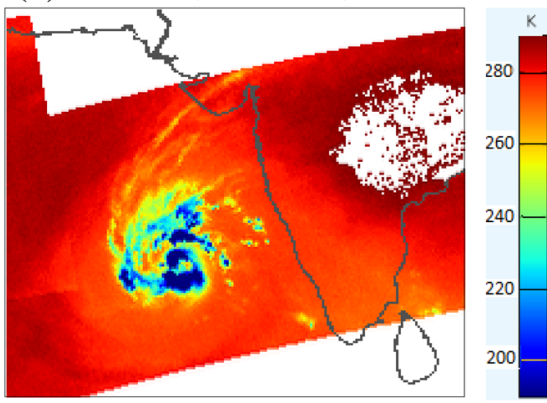

(f) $03-12-2017$ (T4.5 \& 91.8 K)

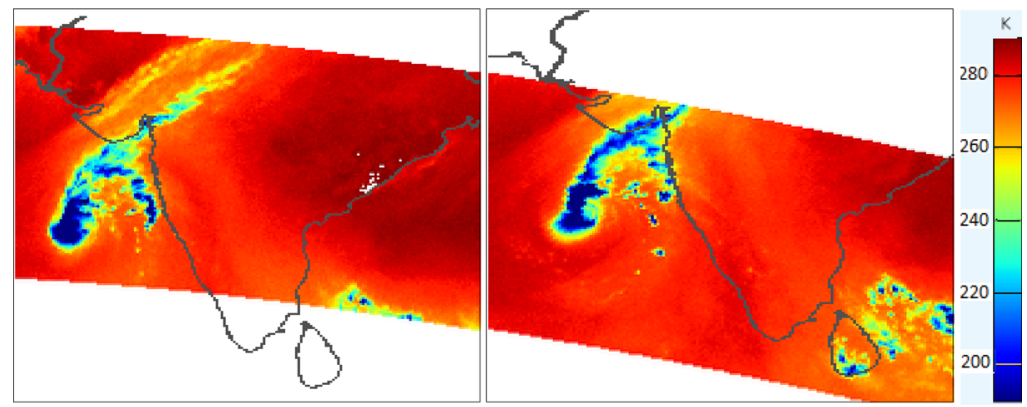

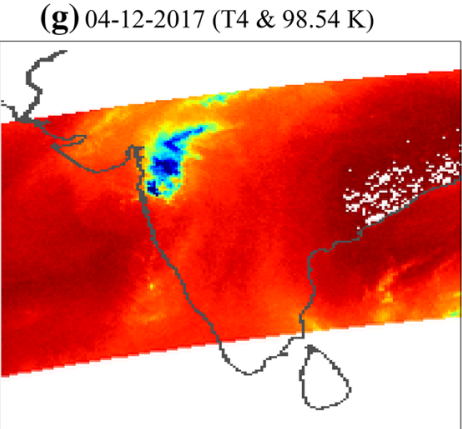

(i) $06-12-2017$ (T2.5 \& $124 \mathrm{~K})$ (h) $05-12-2017$ (T3.5 \& 118.97 K)

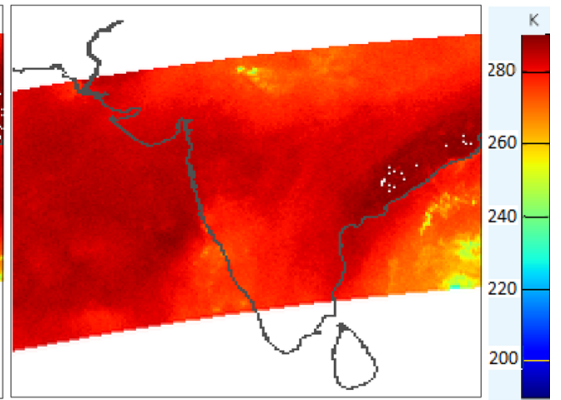

(j) $07-12-2017$ (T1.5 \& 186 K)

Figure 3. (a-j) Observation of very severe cyclonic storm Ockhi cyclone cloud pattern with T-number development along with TB (K) variation over the Bay of Bengal during 28 November to 7 December 2017. 
Table 3. Regression coefficients for position of cyclones.

\begin{tabular}{|c|c|c|c|c|c|c|c|c|c|}
\hline \multirow{2}{*}{$\begin{array}{l}\text { Observed } \\
\text { time }(\mathrm{h}) \\
\end{array}$} & \multirow[b]{2}{*}{$N$} & \multicolumn{4}{|c|}{ Latitude $\left({ }^{\circ} \mathrm{N}\right)$} & \multicolumn{4}{|c|}{ Longitude $\left({ }^{\circ} \mathrm{E}\right)$} \\
\hline & & $\beta_{0}$ & $\beta_{1}$ & $\beta_{2}$ & $\beta_{3}$ & $\beta_{0}^{\mid}$ & $\beta_{1}^{\mid}$ & $\beta_{2}^{\mid}$ & $\beta_{3}^{\mid}$ \\
\hline 12 & 105 & 0.7874 & 1.14424 & -0.40512 & 0.0112 & 0.3682 & -0.4498 & -0.8321 & 0.7940 \\
\hline 15 & 92 & 1.4971 & -1.7635 & 0.93645 & -1.1256 & 1.8554 & 1.6295 & 0.61649 & -1.1503 \\
\hline 18 & 104 & 0.0442 & 0.2453 & 0.4624 & -0.0952 & 0.1518 & 0.3463 & 0.2823 & 0.3356 \\
\hline 21 & 91 & 0.2686 & 0.1349 & -0.3139 & 0.2091 & 0.8525 & 0.1660 & 0.2434 & -0.0802 \\
\hline 24 & 101 & -0.0742 & -0.0307 & -0.1276 & -1.2194 & 0.8821 & 0.8027 & 0.57793 & -0.4609 \\
\hline 36 & 80 & 0.5078 & 0.9976 & -0.01564 & -0.1645 & 5.3802 & 0.0669 & -0.9126 & 0.48339 \\
\hline 48 & 64 & 0.5207 & 0.9789 & 0.05614 & -0.1284 & 3.0610 & 0.5568 & -0.2301 & 0.02481 \\
\hline
\end{tabular}

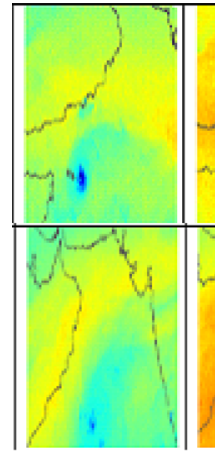

(a) Ch1

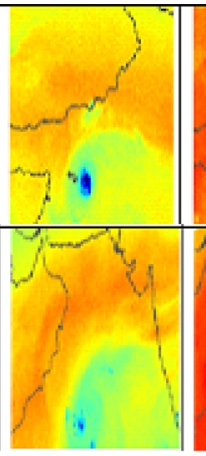

(b) $\mathrm{Ch} 2$

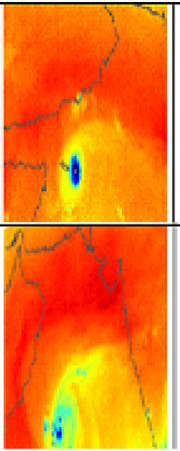

(c) $\mathrm{Ch} 3$

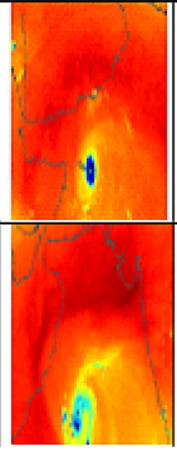

(d) $\mathrm{Ch} 4$

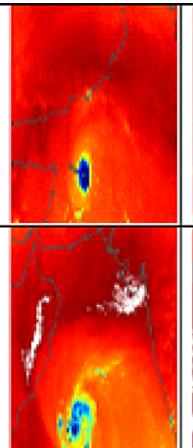

(e) $\mathrm{Ch} 5$

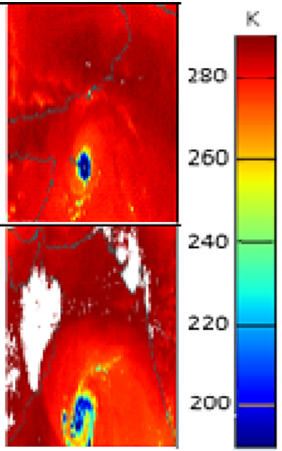

(f) $\mathrm{Ch} 6$

Figure 4. Observation of TC-Chapala (2015) and TC-Megha (2015) occurred in the ARB basin using the SAPHIR sensor (Ch1-Ch6 and TB varies from 200 to $285 \mathrm{~K}$ ).

relating to all the 20 TCs formed over ARB and BOB basins of NIO during 2011-2018 have been used. The observation of Cloud System Center (CSC) using the brightness temperature variations with special reference to the eye of the cyclone and at cyclone eyewall region has been performed. By utilising microwave image from SAPHIR sounder to analyse the cloud spiral structure of cyclones and eye centre positions of TCs, the TCs formed over NIO with information regarding the observed time along with position and duration of cyclone are arranged in two groups, as shown in tables 1 and 2 .

\section{Methodology}

As a general rule, analysis of the cloud pattern formed specifically at the storm cenere identified by the eye of the cyclone and cyclone walls is used for the estimation of TC intensity variations. In our analysis, observation of possibility of classifying TC intensity variations according to the Dvorak procedure by using SAPHIR data is made. According to the Dvorak procedure, features of the cloud of a cyclone will be determined by observing the cloud pattern at CSC. Observation of CSC at every stage of TC storm intensity variations has been made, and depending on the features of the cloud during every stage of TC intensity variations, distinctive TC numbers (or T-numbers) are relegated. Figure 1 shows the procedure involved in every stage of assigning T-number to respective intensity of TC storm under observation. The methodology of studying the TC genesis, intensity development and dissipation data has been conveniently grouped into six stages: in the initial stage, i.e., at the time of indications of deep depression stage of every TC under observation, determination of CSC including the determination of eye region and eyewall formation is made.

The CSC is identified at the centre of the eye of the cyclone or at the partial eyewall when the earlier development of curved cloud into denser clouds for $1-1.5$ days $(>12 \mathrm{~h}$ ) before the cyclone strength. A spiral cloud band wrapped around CSC and a relative warm spot with a diameter of curvature of $1.5^{\circ}$ latitude in size (converting $1^{\circ}$ interval into $2 \mathrm{~km}$ from the cyclone centre) or less are shown in figure 2 (stage 2). 


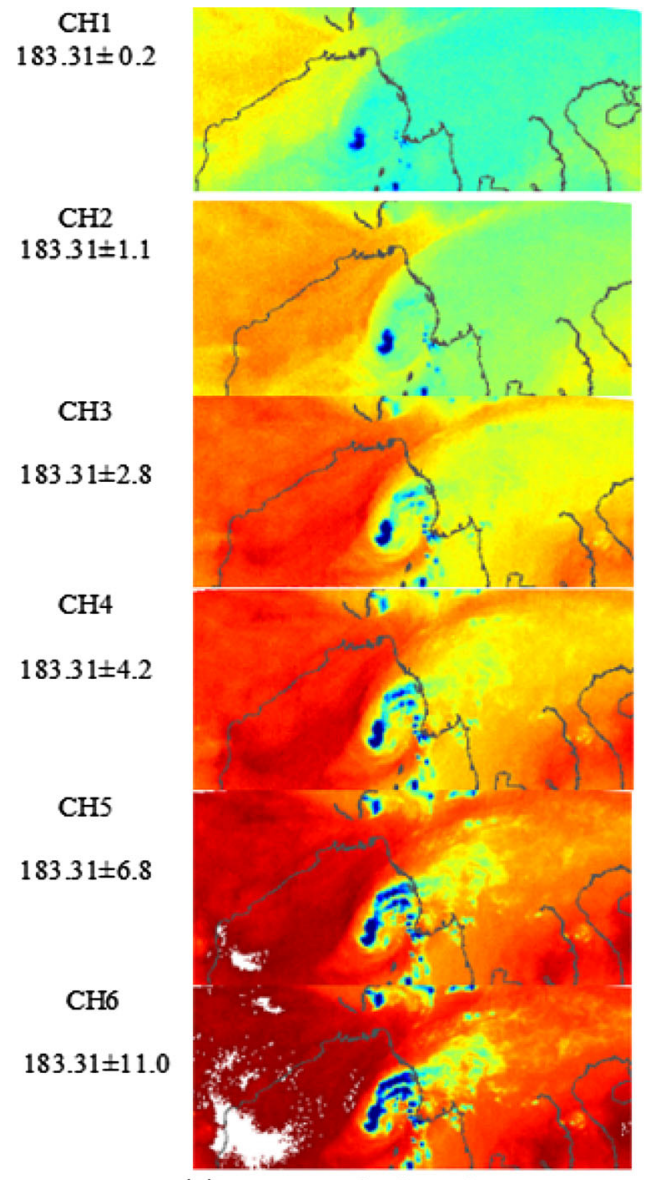

(a) TC-Maarutha (T 2.5)

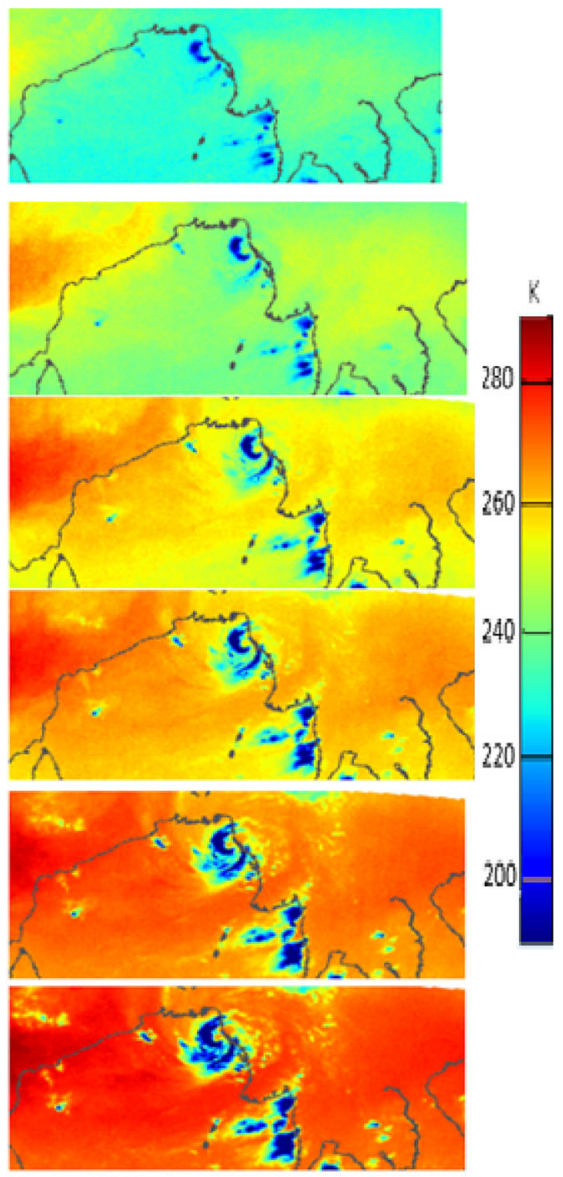

(b) TC-Mora (T 3.5)

Figure 5. (a and b) Observation of TC-Maarutha (2017) and TC-Mora (2017) occurred in the BOB basin using the SAPHIR sensor (Ch1-Ch6 and TB varies from 200 to $285 \mathrm{~K}$ ).

Table 4. Comparison of cyclone location occurred in ARB basin observed by SAPHIR with IMD and RAMMB.

\begin{tabular}{|c|c|c|c|c|c|c|c|c|}
\hline \multirow{2}{*}{$\begin{array}{l}\mathrm{TC} \\
\text { name }\end{array}$} & \multirow{2}{*}{$\begin{array}{l}\text { Peak intensity } \\
\text { date }\end{array}$} & \multirow{2}{*}{$\begin{array}{l}\text { Time } \\
\text { (UTC) }\end{array}$} & \multicolumn{3}{|c|}{ Latitude $\left({ }^{\circ} \mathrm{N}\right)$} & \multicolumn{3}{|c|}{ Longitude $\left({ }^{\circ} \mathrm{E}\right)$} \\
\hline & & & SAPHIR & IMD & RAMMB & SAPHIR & IMD & RAMMB \\
\hline Keila & 02 November 2011 & 12.00 & 16.3 & 16.5 & 17.0 & 54.2 & 54.5 & 55.0 \\
\hline Murjan & 24 October 2012 & 18.00 & 10.2 & 10.5 & 10.5 & 55.0 & 55.5 & 55.3 \\
\hline Nanauk & 11 June 2014 & 06.00 & 16.5 & 16.9 & 16.9 & 66.38 & 66.7 & 66.7 \\
\hline Nilofar & 28 October 2014 & 12.00 & 16.5 & 16.7 & 16.8 & 61.7 & 61.8 & 61.8 \\
\hline Ashobaa & 10 June 2015 & 06.00 & 21.0 & 21.3 & 21.1 & 61.4 & 61.5 & 61.5 \\
\hline Chapala & 30 October 2015 & 09.00 & 14.0 & 14.2 & 14.2 & 60.5 & 60.8 & 61.1 \\
\hline Megha & 08 November 2015 & 03.00 & 12.4 & 12.7 & 12.8 & 55.2 & 55.6 & 56.1 \\
\hline Sagar & 18 May 2018 & 18.00 & 11.5 & 11.6 & 11.3 & 45.5 & 45.4 & 45.1 \\
\hline Mekunu & 25 May 2018 & 12.00 & 16.4 & 16.6 & 16.5 & 54.3 & 54.8 & 54.6 \\
\hline
\end{tabular}

In stage 3, contrasting observation of image showing features of the CSC during every 24/12 h period has been made and our observation reveals subjective improvement in the analysis of variation in TC intensity. The cloud pattern of the previous $24 / 12 \mathrm{~h}$ intensity change is resolved subjectively by contrasting the features of the cloud of the present image and decreasing the T-number by 0.5 (stage 4) (i.e., when the brightness temperature changes from 91.97 to $98.09 \mathrm{~K}$ within $24 \mathrm{~h}$, then the T-4 decreased to T-3.5 as shown in figure 3 (h and i, Vardah cyclone). The next step (stage 5) with respect to TC under observation is to identify the well-marked CSC. Generally, the TC cloud 
Table 5. Comparison of cyclone location occurred in the BOB basin observed by SAPHIR with IMD and RAMMB.

\begin{tabular}{|c|c|c|c|c|c|c|c|c|}
\hline \multirow{2}{*}{$\begin{array}{l}\mathrm{TC} \\
\text { name }\end{array}$} & \multirow{2}{*}{$\begin{array}{l}\text { Peak intensity } \\
\text { date }\end{array}$} & \multirow{2}{*}{$\begin{array}{l}\text { Time } \\
(\mathrm{UTC})\end{array}$} & \multicolumn{3}{|c|}{ Latitude $\left({ }^{\circ} \mathrm{N}\right)$} & \multicolumn{3}{|c|}{ Longitude $\left({ }^{\circ} \mathrm{E}\right)$} \\
\hline & & & SAPHIR & IMD & RAMMB & SAPHIR & IMD & RAMMB \\
\hline Thane & 28 December 2011 & 12.00 & 12.4 & 12.5 & 12.0 & 84.4 & 84.5 & 84.1 \\
\hline Nilam & 31 October 2012 & 09.00 & 11.2 & 11.5 & 12.0 & 80.8 & 81.0 & 81.1 \\
\hline Viyaru & 15 May 2013 & 18.00 & 18.9 & 19.0 & 19.6 & 88.4 & 88.5 & 89.1 \\
\hline Phailin & 11 October 2013 & 00.00 & 15.8 & 16.0 & 15.8 & 88.4 & 88.5 & 88.8 \\
\hline Helen & 22 November 2013 & 03.00 & 16.0 & 16.2 & 16.2 & 81.5 & 81.7 & 82.0 \\
\hline Lehar & 11 November 2013 & 21.00 & 12.3 & 12.5 & 12.2 & 91.0 & 91.0 & 91.1 \\
\hline Madi & 08 December 2013 & 15.00 & 9.8 & 10.0 & 13.0 & 84.0 & 84.0 & 84.8 \\
\hline Hudhud & 11 October 2014 & 18.00 & 16.2 & 16.4 & 16.6 & 84.3 & 84.7 & 84.6 \\
\hline Komen & 30 July 2015 & 00.00 & 21.5 & 21.7 & NA & 91.0 & 91.2 & NA \\
\hline Roanu & 21 May 2016 & 06.00 & 19.80 & 21.9 & 22.0 & 93.83 & 91.0 & 91.0 \\
\hline Kyant & 26 October 2016 & 03.00 & 16.4 & 16.6 & 16.6 & 88.2 & 88.5 & 88.5 \\
\hline Nada & 30 December 2013 & 03.00 & 08.0 & 08.2 & 08.6 & 85.1 & 85.3 & 85.7 \\
\hline Vardha & 11 December 2016 & 06.00 & 13.0 & 13.3 & 12.9 & 82.8 & 83.0 & 83.7 \\
\hline Maarutha & 16 April 2017 & 06.00 & 16.9 & 17.0 & 16.8 & 92.8 & 92.9 & 92.6 \\
\hline Mora & 17 May 2017 & 12.00 & 1837 & 18.6 & 18.6 & 91.7 & 91.5 & 91.7 \\
\hline Ockhi & 02 December 2017 & 18.00 & 10.5 & 10.8 & 11.3 & 69.7 & 69.7 & 69.8 \\
\hline
\end{tabular}

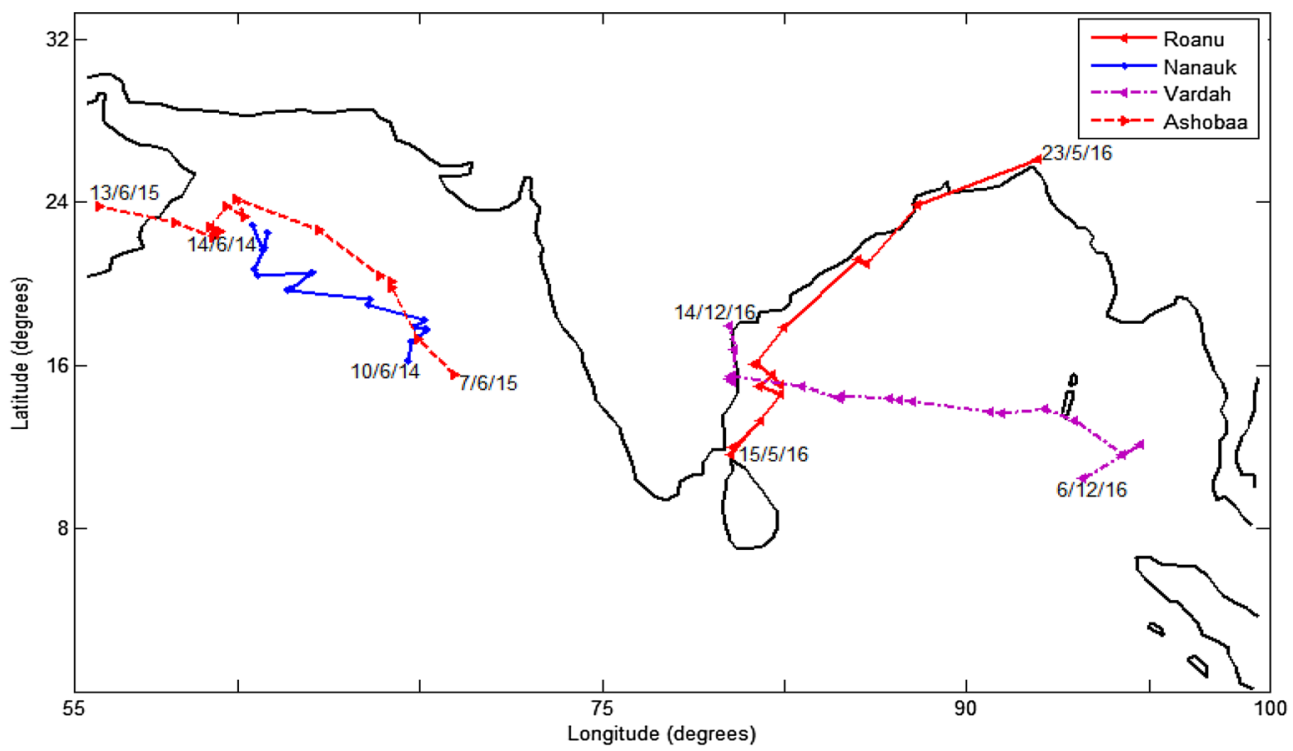

Figure 6. Cyclone path in the Arabian Sea and Bay of Bengal basins.

system has a well-marked CSC located within a diameter of $2.5^{\circ}$ or $<2.5^{\circ}$ and will lasts for $6 \mathrm{~h}$. If the TC cloud system has a CSC of $1.5^{\circ}$ latitude or $<2^{\circ}$ latitude in diameter, then at that point, assign the T-number by 0.5 . For every increase of $0.5^{\circ}$ latitude in diameter of CSC, increment the T-number by 0.5 . The final stage of observation (stage 6 ) is to ascertain the maximum period of peak intensity. It is observed that most storms retain their maximum intensity for first 24-48 h. However, certain unique storms will retain peak intensity even after 3-4 days after T-number determination (Velden et al. 2006).

Generally, the TC latitude and longitude positions are estimated and/or monitored by using the multiple linear regression method. In the linear regression method, for every time interval from 12 to $72 \mathrm{~h}$, the observed latitude and longitude positions of TC locations are linearly relapsed. The linear relationship between the set of dependent variable (predictant) and sets of independent variables (predictors) has been described in 


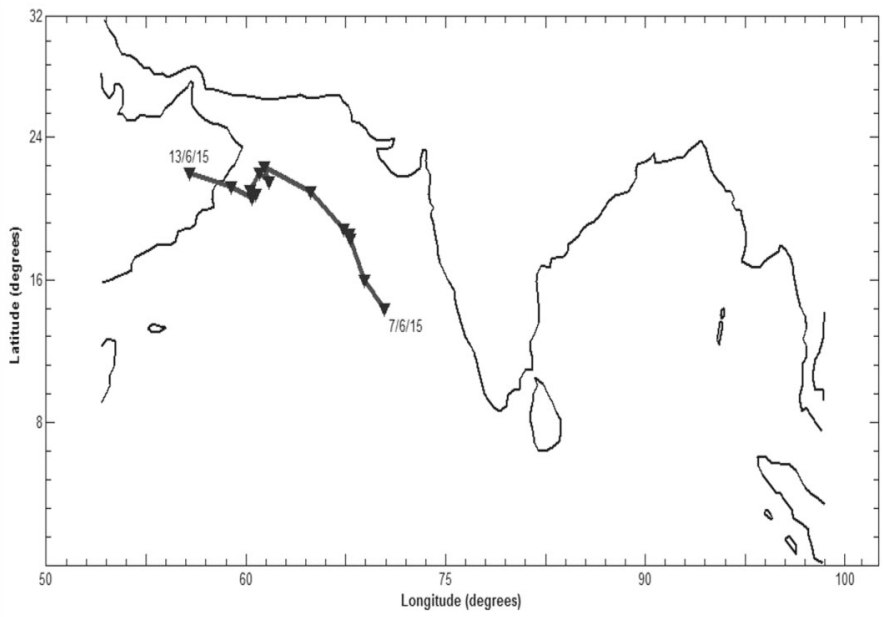

(a) Cyclonic storm Ashobaa path

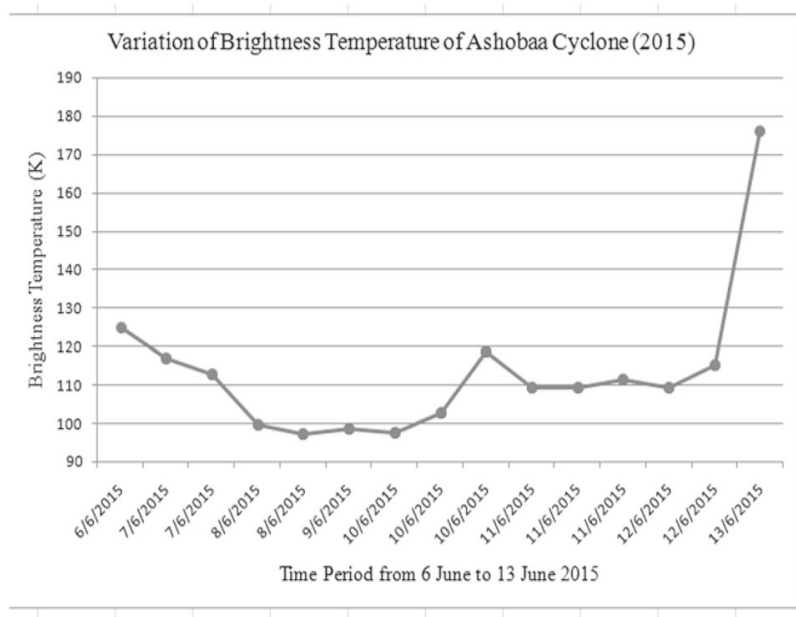

(b) Brightness temperature variation

Figure 7. (a and b) Cyclonic storm Ashobaa during 6-13 June 2015.

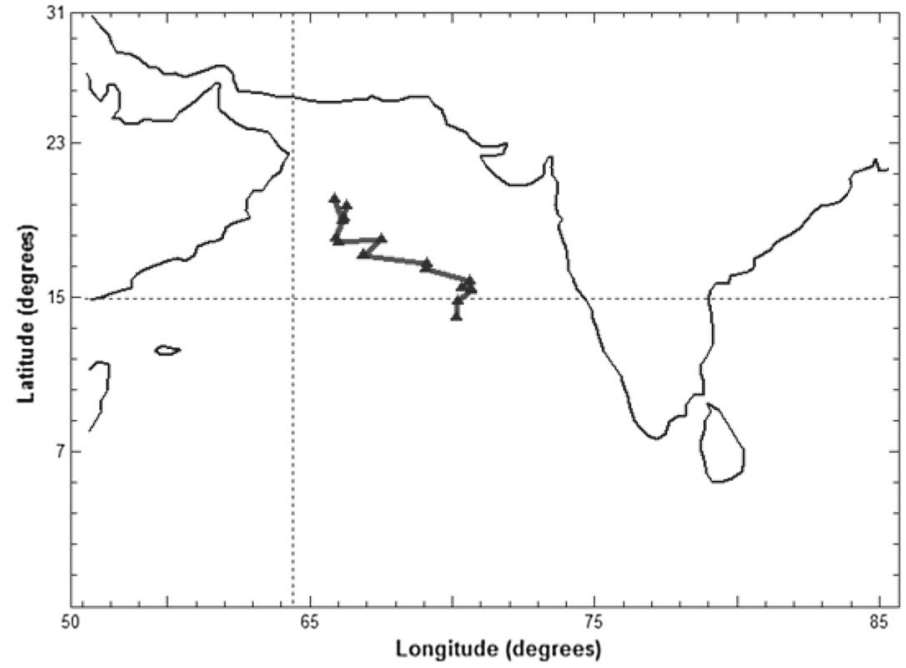

(a) Track of Cyclonic storm Nanauk

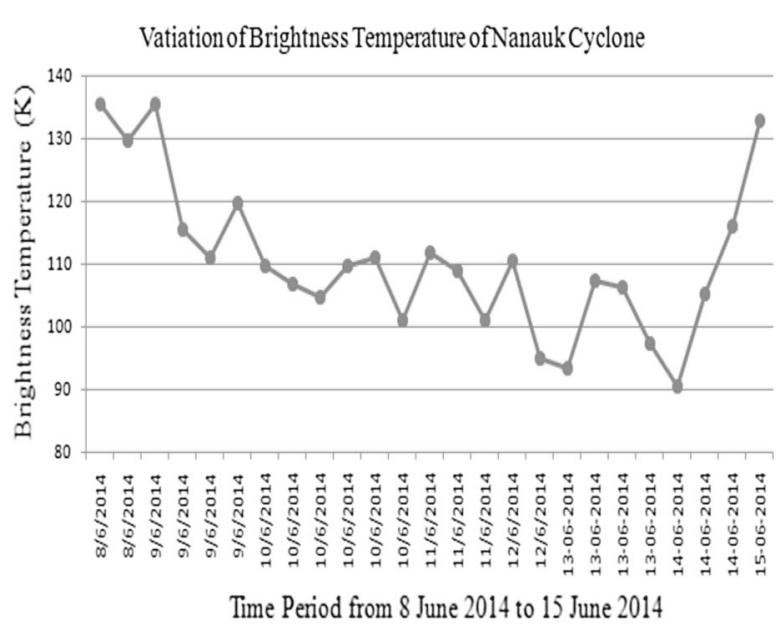

(b) Brightness temperature variation

Figure 8. (a and b) Cyclonic storm Nanauk during 8-15 June 2014.

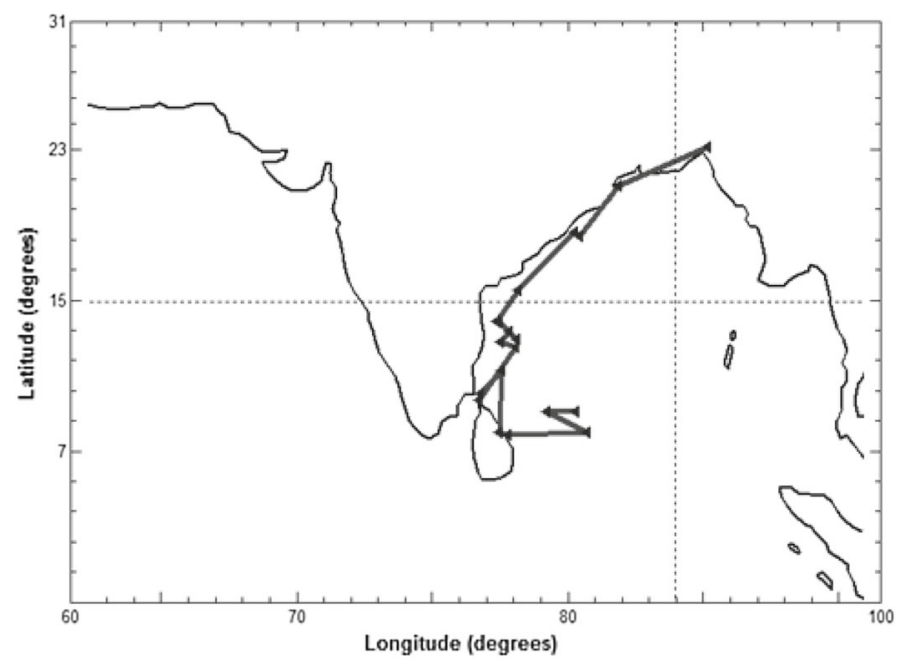

(a) Track of Cyclonic storm Roanu

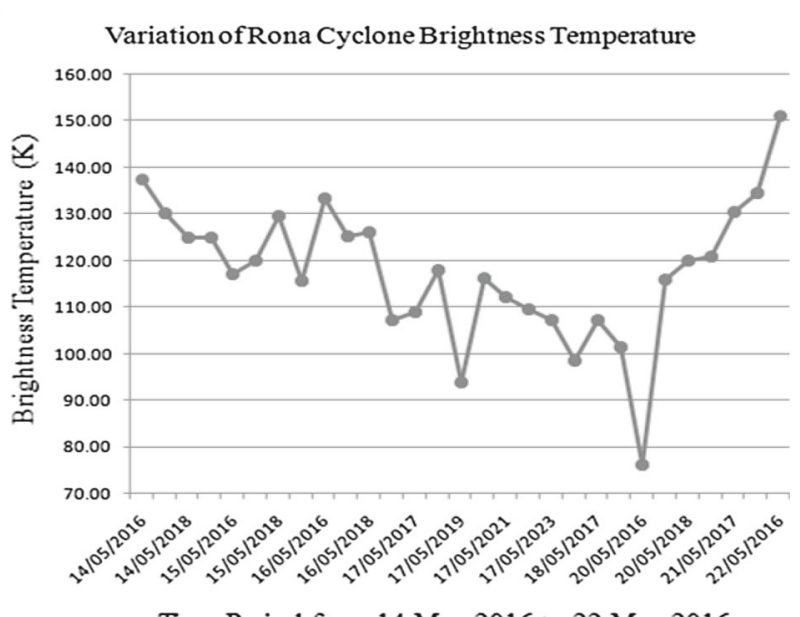

Time Period from 14 May 2016 to 22 May 2016

(b) Brightness temperature variation

Figure 9. (a and b) Cyclonic storm Roanu during 14-22 May 2016. 
the multiple linear regression equation, presented as

$$
y=\beta_{0}+\beta_{1} x_{1}+\beta_{2} x_{2}+\cdots+\beta_{n} x_{n},
$$

where the predictors are $x_{1}, x_{2}, \ldots, x_{n}$, predictant is $y$ and $\beta_{1}, \beta_{2}, \ldots, \beta_{n}$ are expressed as regression coefficients. Dataset relating to TCs formed during pre- and post-monsoon seasons over the NIO has been used to determine the regression coefficients. In our observation, the latitude and longitude positions at 12, 15, 18, 21, 24, 36 and $48 \mathrm{~h}$ intervals of time have been chosen to monitor the TCs under observation for evaluation according to equations (2) and (3).

$$
\begin{aligned}
\operatorname{Long}_{t}= & \beta_{0}+\beta_{1} \mathrm{SAPHIR}_{t}^{\text {long }}+\beta_{2} \mathrm{ECMWF}_{t}^{\text {long }} \\
& +\beta_{3} \mathrm{JMA}_{t}^{\text {long }} \\
\text { Lat }_{t}= & \beta_{0}^{\mid}+\beta_{1}^{\mid} \mathrm{SAPHIR}_{t}^{\text {lat }}+\beta_{2}^{\mid} \mathrm{ECMWF}_{t}^{\text {lat }} \\
& +\beta_{3}^{\mid} \mathrm{JMA}_{t}^{\text {lat }}
\end{aligned}
$$

where Long $_{t}$ is the longitude at observed time $t$; Lat $_{t}$ is the latitude at observed time $t ; t$ is the observation time interval $12,15,18,21,24,36$ and $48 \mathrm{~h}$; SAPHIR $t$ lat is the observed latitude at $t$ time from SAPHIR sensor; and SAPHIR long is the observed longitude at $t$ time from SAPHIR sensor. For every observation made at different time intervals, regression analyses have been applied for estimates of cyclone positions. The dependent variables latitude (Lat) in ${ }^{\circ} \mathrm{N}$ and longitude (Long) in ${ }^{\circ} \mathrm{E}$ are the predictants, the constant $\left(\beta_{0}, \beta_{0}^{\mid}\right)$and the coefficients $\left(\beta_{1}, \beta_{2}, \beta_{3}, \beta_{1}^{\mid}, \beta_{2}^{\mid}\right.$and $\left.\beta_{3}^{\mid}\right)$for latitude and longitude; $N$ is the number of samples at each observation time interval (table 3). From table 3 , if the regression coefficients in both latitude and longitude (i.e., in $\beta_{0}, \beta_{1}, \beta_{2}, \beta_{3}, \beta_{0}^{\mid}, \beta_{1}^{\mid}, \beta_{2}^{\mid}$and $\left.\beta_{3}^{l}\right)$ are positive values, then the direction changes in $x$ and $y$ variables is in the same direction, and if the regression coefficients in both latitude and longitude (i.e., $\beta_{0}, \beta_{1}, \beta_{2}, \beta_{3}, \beta_{0}^{\mid}, \beta_{1}^{\mid}$, $\beta_{2}^{\mid}$and $\beta_{3}^{\mid}$) are negative values, then the direction changes in $x$ and $y$ variables is in opposite directions.

\section{Observation and analyses}

In this section, the analysis of the TC genesis and developing stages of cyclone over the NIO is discussed qualitatively. The same methodology has been applied to all the 25 cyclones listed in tables 1 and 2 that occurred in the ARB and BOB basins

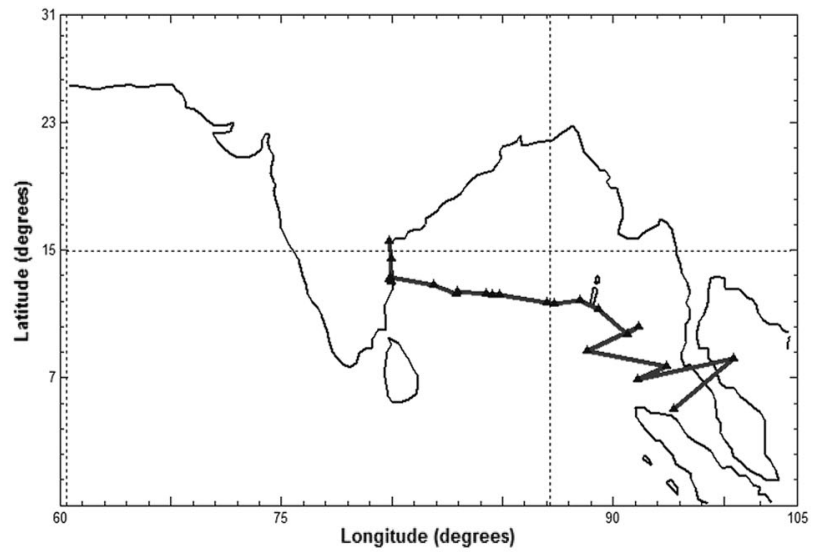

(a) Track of VSCS Vardah

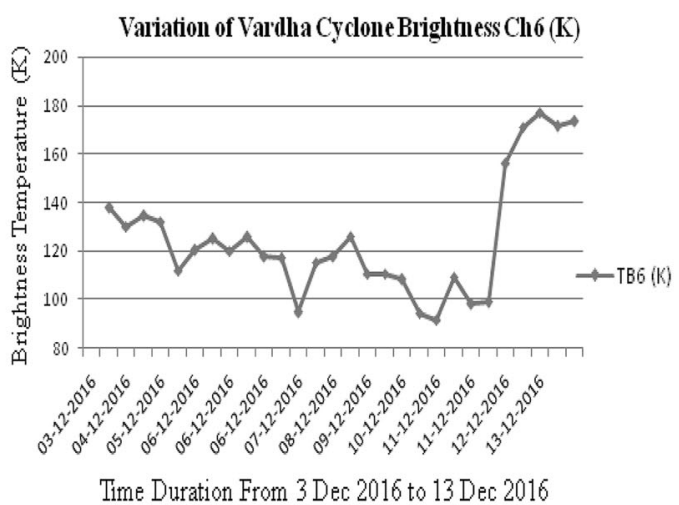

(b) Brightness temperature variation

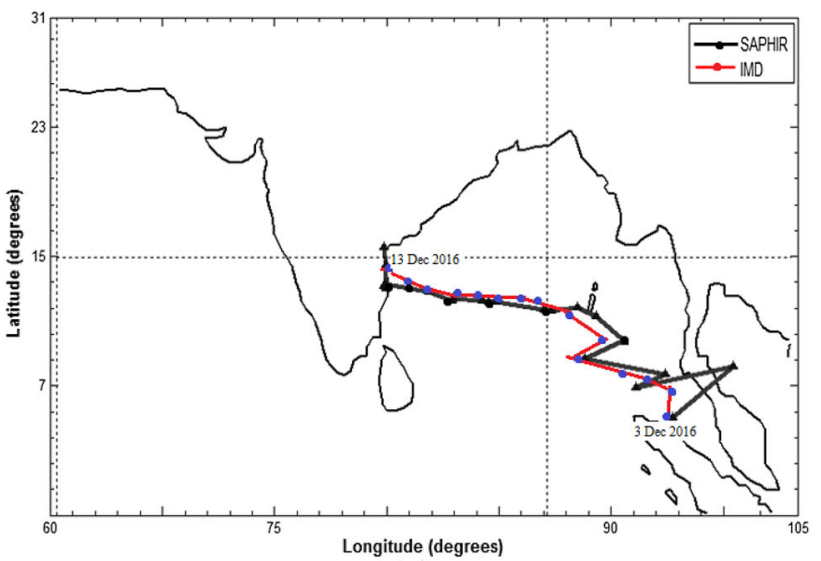

(c)

Figure 10. (a and b) Very severe cyclonic storm (VSCS) Vardah during 3-13 December 2016. (c) Tracking of cyclone comparison from SAPHIR and IMD best track of VSCS Vardah during 3-13 December 2016.

surrounding the Indian sub-continent from 2011 to 2018 .

The very severe cyclonic storm Ockhi occurred in the BOB basin, as shown in figure $3(\mathrm{a}-\mathrm{j})$, the satellite observed the evolution of cyclone storm progress in terms of cyclonic cloud pattern 


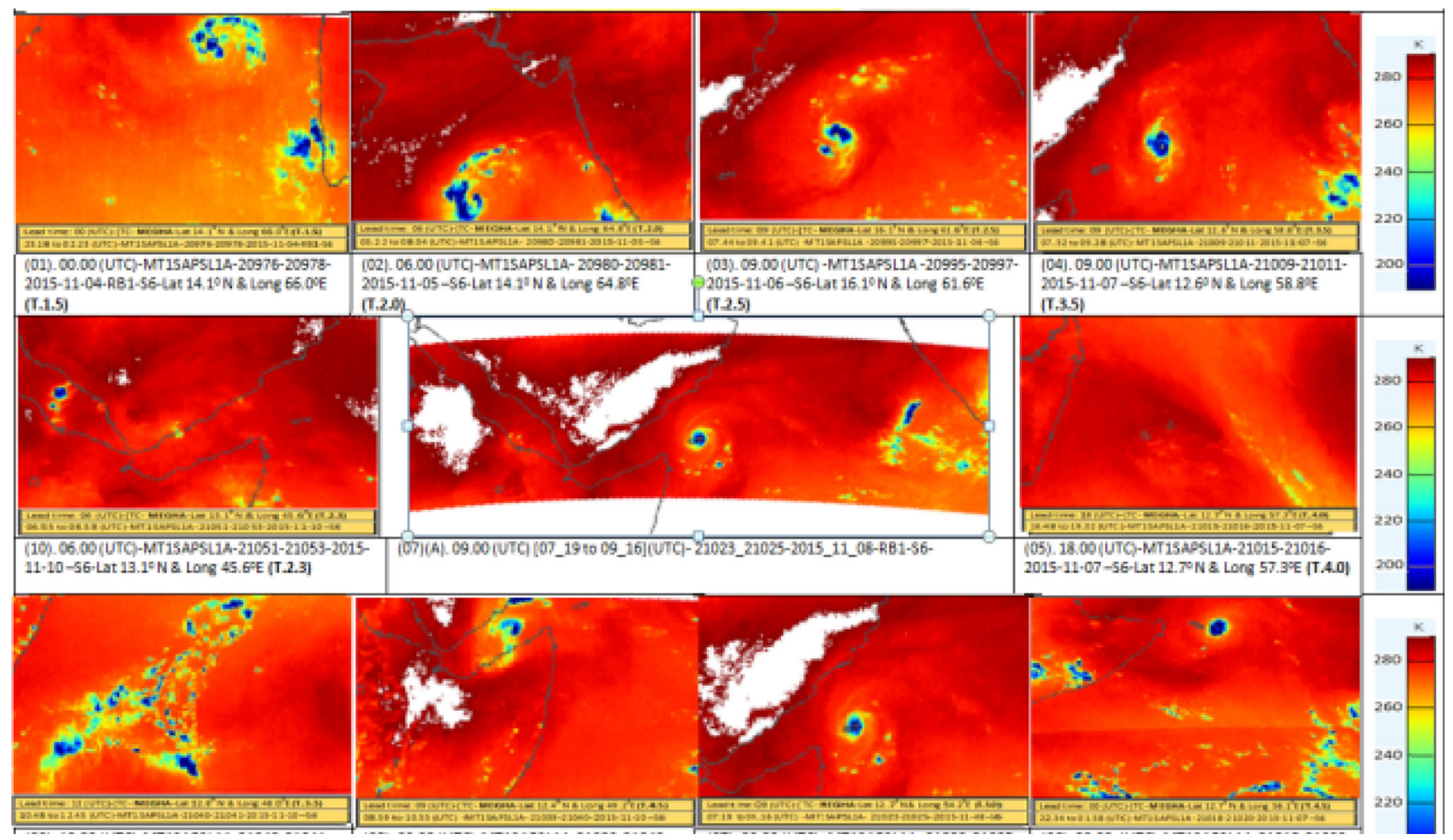

Figure 11. Tropical cyclone Megha (2015) occurred in the Arabian Sea (SAPHIR and TB varies from 200 to 285 K).

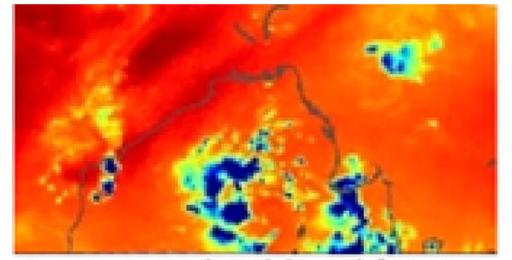

Day-01-00.00-(UTC)-(T-1.5)-[00.33 to 02.23 (UTC) 29028_29029-S6]

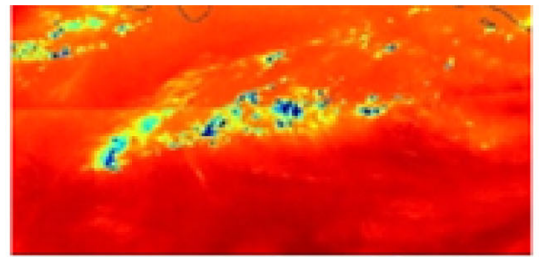

Day-01-09.00-(UTC)-(T-2.0)-[07.45 to 10.52 (UTC)-29032_29034-S6]

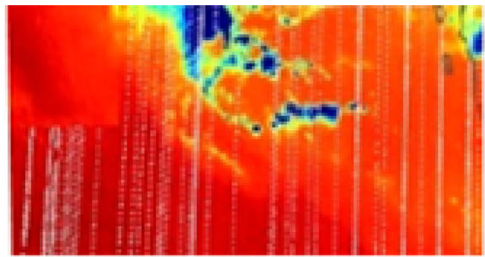

Day-01-18.00-(UTC)-(T-2.5]- [16.38 to 19.50 (UTC)-29037_29039-S6]

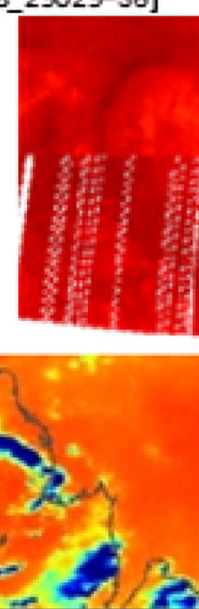

Day-02-00.00-(UTC)-(T-3.0)- [22.25 to 00.22 (UTC) $29041 \_29042-\$ 6$ ]
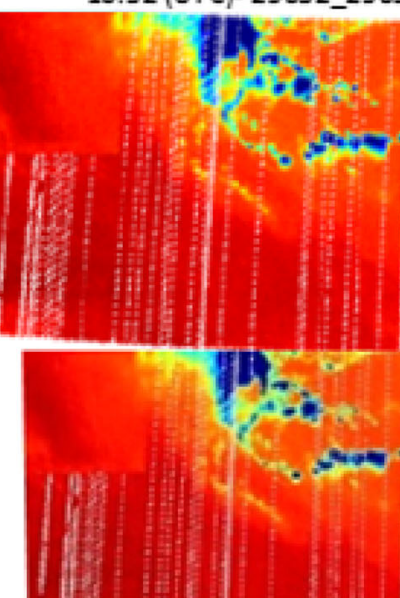

Day-02-18.00-(UTC)-(T-3.5)-[16.26 to 18.45 (UTC)- 29051_290S2-S6]

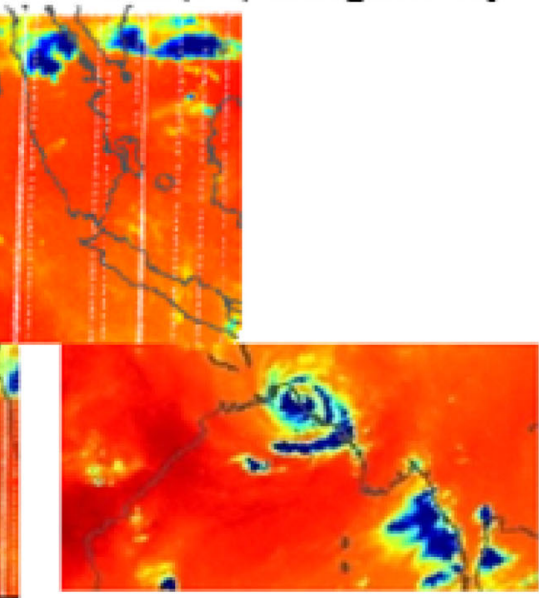

Day-08-03.00-fuTC)-(T-3.5]- [01.53 to 03.49 (UTC) -29057_29058-S6]

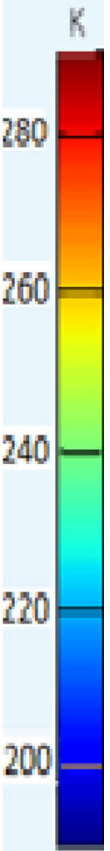

Figure 12. Tropical cyclone Mora (2017) occurred in the Bay of Bengal (SAPHIR and TB varies from 200 to 285 K). 
of the day when a storm is likely to reach the maximum intensity. Figure $3(\mathrm{a}-\mathrm{j})$ shows the life cycle of the Ockhi cyclone from genesis on 29 November 2016 to dissipation 6 December 2017 at 24-h intervals, which persisted for a longer period and made landfall after $162 \mathrm{~h}$. The spiral cloud structure formation shows a day-by-day increase in the coiling of its cloud at the same rate as that depicted along with the brightness temperature variation. During the pre-storm stage, from the SAPHIR sensor, the observed brightness temperature is $136.48 \mathrm{~K}$ at the initial stage, i.e., partial eyewall region and cloud structure of cyclone development which are defined as low-pressure area on 28 November 2017. The intensity variation continues at the rate of T- 0.5 to T-1.5 on 29 November 2017 and is increased by the length of the convective clouds and simultaneously decreasing in brightness temperature. On 2 December to 3 December 2017, a tight cloud band curvature that increased by $\leq 1.5^{\circ}$ latitude in diameter indicates the increase in intensity from T-4 to T-4.5 and reduction in brightness temperature from 106.3 to $91.8 \mathrm{~K}$ which has been observed after $24 \mathrm{~h}$ of the current observation. It starts to break down in intensity after hit or crossed over South Gujarat Coast between Surat and Dahanu and reaches back to normal brightness temperature $186 \mathrm{~K}$.

The variation of CSC near TC eye and cloud eyewall area plays a unique role in measuring the TC intensity. During the peak intensity period of all 25 TCs formed over the NIO region, the brightness temperature measurements relating to variation of CSC along with their variation near TCs eye and cloud eyewall area were measured from all six channels (Ch1-Ch6) of SAPHIR sounder. It is observed that the dataset obtained from $\mathrm{Ch} 6$ is found to be suitable for observation of TC eye and cloud eyewall area variation. Figure 4 shows the observations of TC-Chapala (2015) and TC-Megha (2015) which occurred in ARB basin, and figure 5(a and b) shows the observations of Maarutha cyclone (2017) and Mora cyclone (2017) which occurred in the BOB basin that were observed by the SAPHIR sensor. Satellite imagery with brightness temperature from left to right shows the channels from Ch1 to Ch6 of Maarutha and Mora cyclones. The corresponding cyclones that occurred over ARB (during 2011-2018) are (i) TC-Keila, ARB basin, T-2.5; (ii) TC-Murjan, ARB basin, T-2.5; (iii) TC-Nanauk, ARB basin, T-3; (iv) TC-Nilofar, ARB basin, T-5.5; (v) TC-Ashobaa, ARB basin, T-3; (vi) TCChapala, ARB basin, T-6; (vii) TC-Megha, ARB

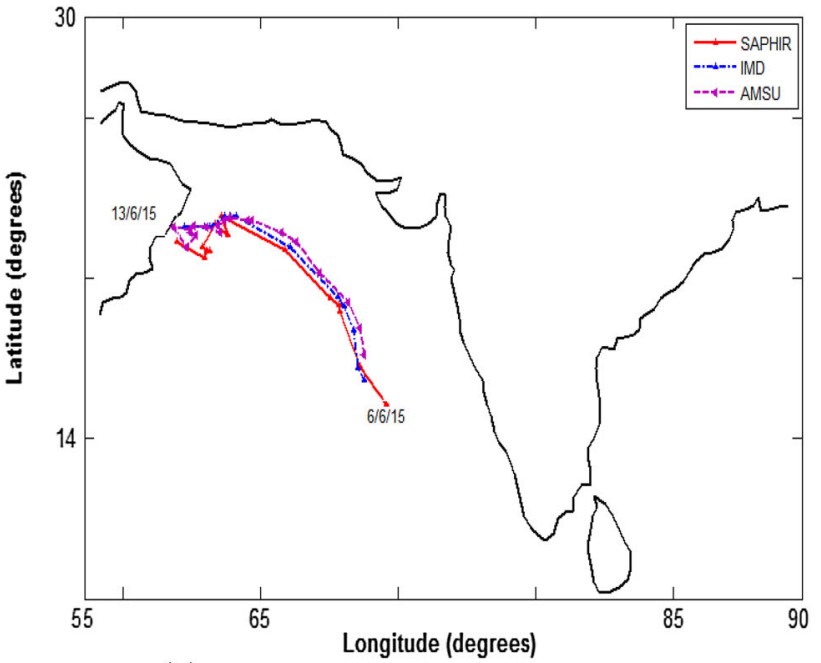

(a) Cyclonic storm Ashobaa in ARB (2015)

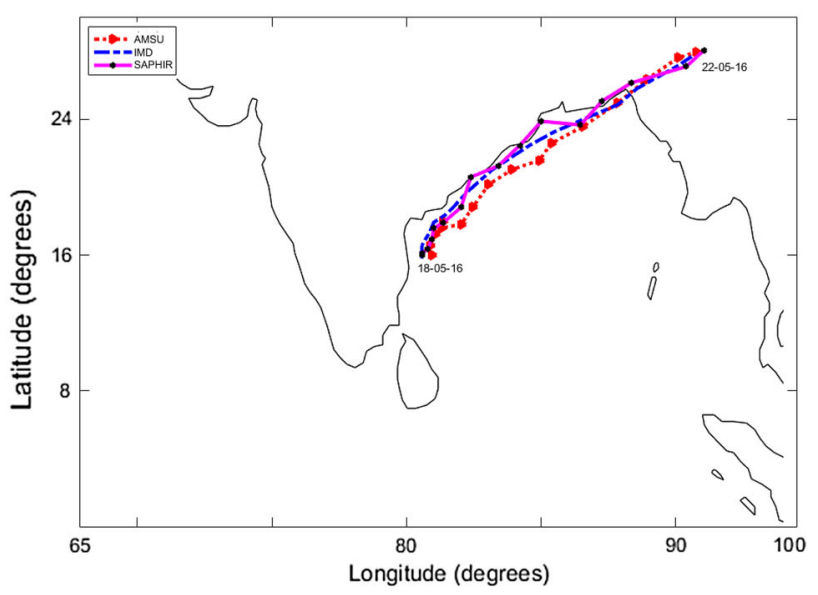

(b) Cyclonic storm Roanu in BOB (2016)

Figure 13. (a and $\mathbf{b})$ Comparison of tracking of cyclone from SAPHIR, IMD and AMSU datasets.

basin, T-5; (viii) TC-Sagar, ARB asin, T-3; and (ix) TC-Mekunu, ARB basin, T-4.5.

Table 4 shows the comparison of latitude and longitude positions of TC formed in the ARB basin during 2011-2018 with special reference to the date of attaining peak intensity of each cyclone based on the observation of SAPHR data and best track record reported by Indian Meteorological Department (IMD) and Regional and Mesoscale Meteorology Branch (RAMMB). Similarly, table 5 shows the comparison of latitude and longitude positions of TC formed in the BOB basin during 2011-2018. The satellite observation of position of TCs during 2011-2018 using the SAPHR dataset shows only marginal variation of mean error $0.2-$ $0.3^{\circ}$. This variation may be the result caused due to different algorithms made by the respective departments and/or due to in situ corrections. 


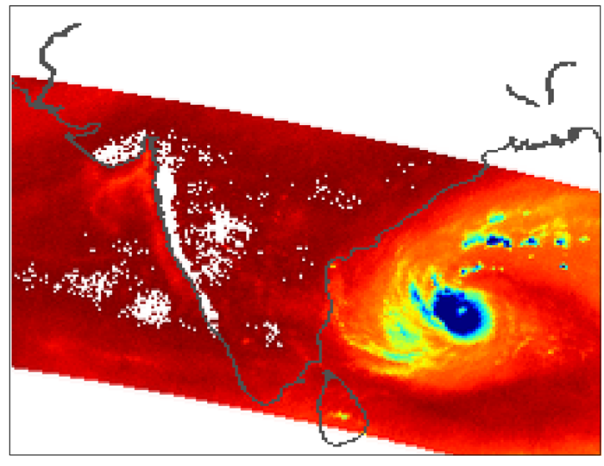

(a) SAPHIR observed on 10-12-2016 (T3.5)

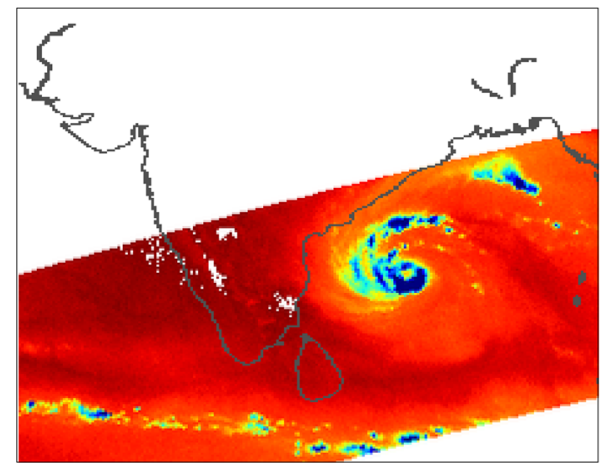

(c) SAPHIR observed on 11-12-2016 (T4)

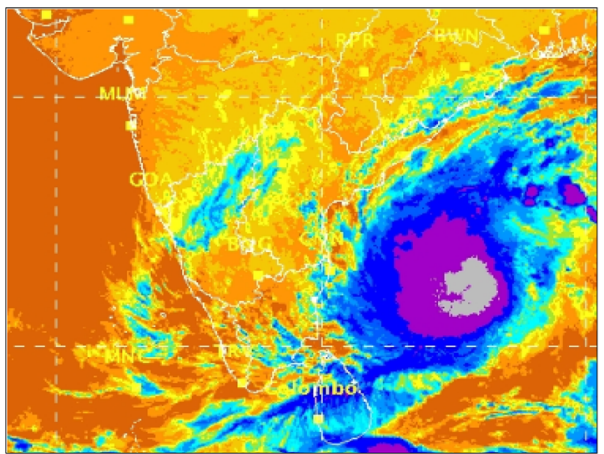

(b) INSAT 3D IR observed on 10-12-2016 (T3.5)
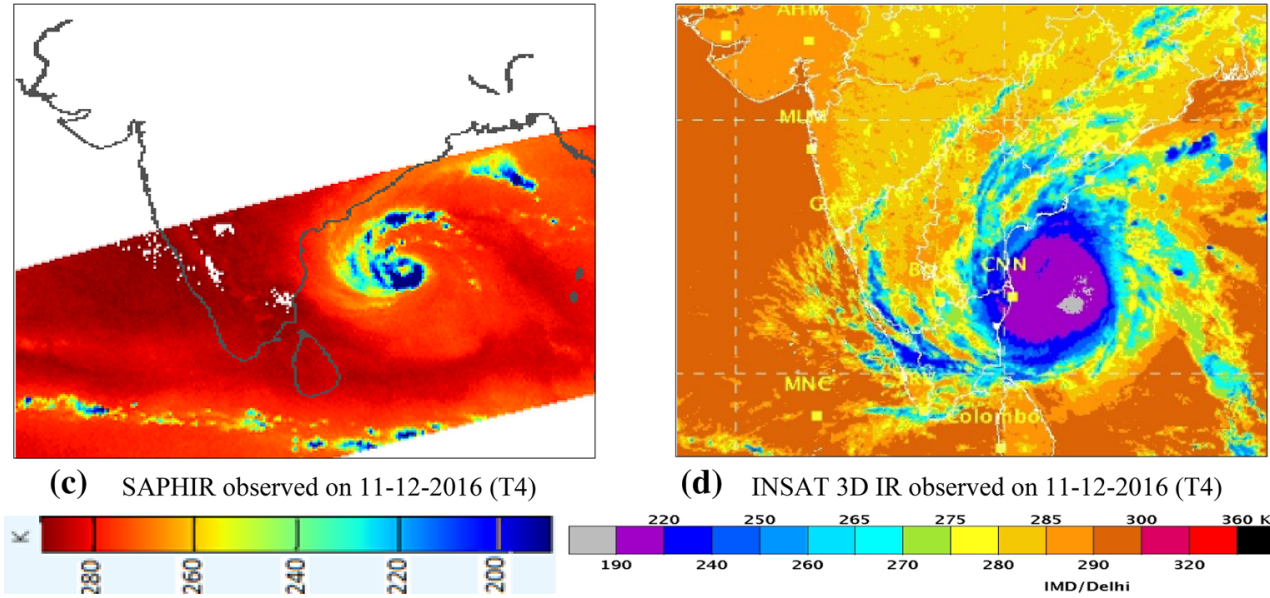

(d) INSAT 3D IR observed on 11-12-2016 (T4)

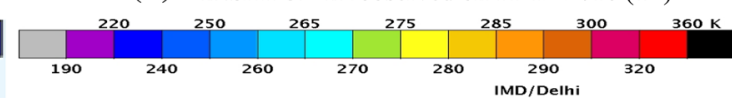

Figure 14. SAPHIR observation compared with INSAT 3D IR of very severe cyclonic storm Vardah on 10 December 2016 and 11 December 2016.

\section{Results and discussion}

In this section, monitoring of latitude and longitude positions of TC using the SAPHIR sounder scientific data has been discussed. Cyclone paths of two cyclones occurred in the ARB basin (Ashobaa and Nanauk) and two cyclones occurred in the BOB basin (Rona and Vardah) from genesis to dissipation have been shown in figure 6 are considered for observation from 22 cyclones.

In the year 2015, during 7-13 June, a tropical cyclonic storm Ashobaa originated at $13.5-20.9^{\circ} \mathrm{N}$ latitudes and $69.6-56.2^{\circ} \mathrm{E}$ longitudes of east central ARB basin of NIO and moved towards the Oman costal region before landfall. The latitude vs. longitude track position of the cyclonic storm Ashobaa is shown in figure 7(a). In the year 2014 during 8-15 June, the tropical cyclonic storm Nanauk originated at $14.09-20.05^{\circ} \mathrm{N}$ latitudes and $67.9-62.6^{\circ} \mathrm{E}$ longitudes of east central ARB basin of NIO and weakened towards west central ARB and the latitude vs. longitude track position of the cyclonic storm Nanauk is shown in figure $8(\mathrm{a})$. In the year 2016 during 14-22 May, the tropical cyclonic storm Roanu originated at $8.4-23.06^{\circ} \mathrm{N}$ latitudes and $80-91.68^{\circ} \mathrm{E}$ longitudes of southwest BOB of Sri Lanka coast of NIO and weakened towards northeastwards of Manipur. The latitude vs. longitude track position of the cyclonic storm Roanu is shown in figure 9(a). In the year 2016 during 6-13 December, the VSCS Vardah originated at $8.4-23.06^{\circ} \mathrm{N}$ latitudes and $80-91.68^{\circ} \mathrm{E}$ longitudes of south Andaman Sea and adjoining southeast BOB basin over NIO and weakened towards north Tamil Nadu coast and the latitude vs. longitude track position of VSCS Vardah is shown in figure 10(a). The variation in brightness temperature $(\mathrm{K})$ of $\mathrm{TC}$ Ashobaa before the eye of the cyclone formed and weakened towards the Oman costal region is shown in figure 7(b). On 8 June 2015, TB reached a minimum of $97.4 \mathrm{~K}$ before it got weakened, and on 13 June 2015, it reached back to normal temperature, i.e., $177 \mathrm{~K}$ during its movement towards the Oman costal region. The variation in brightness temperature of TC Nanauk before the eye of the cyclone formed and weakened towards east central ARB 


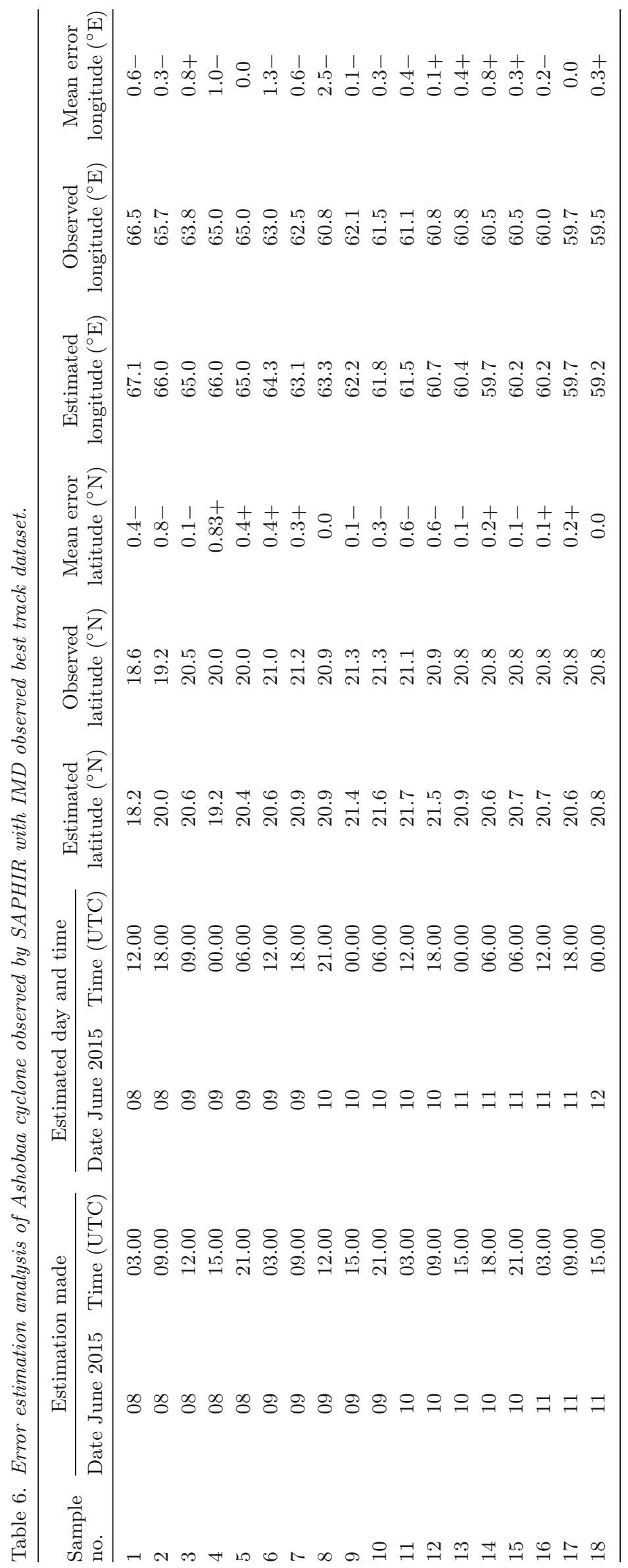


region is shown in figure $8(\mathrm{~b})$. When complete eye is formed, the TB reached a minimum of $93.6 \mathrm{~K}$, before it got weakened, and on 15 June 2014, it reached back to normal temperature, i.e., $132.9 \mathrm{~K}$ during its movement towards west central ARB. The variation in brightness temperature of $\mathrm{TC}$ Roanu before the eye of the cyclone formed and weakened towards southwest BOB of Sri Lanka is shown in figure 9(b). On 20 May 2016, TB reached a minimum of $76.36 \mathrm{~K}$, before it got weakened, and on 22 May 2016, it reached back to normal temperature, i.e., $151.32 \mathrm{~K}$ during its movement towards eastwards BOB near the Manipur region. In the year 2016 during 6-13 December, VSCS Vardah, TB reached a minimum of $91 \mathrm{~K}$ on 11 December 2016 and reached back to normal temperature, i.e., 177.2 K after landfall towards north Tamil Nadu coast. Figure 10(c) shows the observation made from SAPHIR dataset, and comparison with IMD best track shows that the marginal variations in the position of cyclone is $0.2-0.3^{\circ}$ of VSCS Vardah cyclone which occurred on 3 December 2016 and landfall on 13 December 2016.

The observation of progress in the eye of the cyclone development starting from cyclone genesis period up to its dissipation with reference to cyclone Megha generated in the ARB basin of NIO from SAPHIR brightness temperature dataset is shown in figure 11. The observation of progress in the eye of the cyclone development starting from cyclone genesis period up to its dissipation with reference to cyclone Mora generated in the BOB basin of NIO from SAPHIR brightness temperature dataset is shown in figure 12 . Progressive development of cyclone eye with reference to TCs Megha (2015) and Mora (2017) occurred in NIO and shown in figures 11 and 12 explicitly exhibits CSC along with variation in cloud curvature band from genesis to dissipation near eyewall area is observed during lead time of 24-h interval and our observation shows day-to-day increase of cloud curvature band in cloud eyewall area.

In figure 13( $\mathrm{a}$ and $\mathrm{b})$, cyclone storms showing the track of cyclones occurred over NIO by using datasets from SAPHIR, compared with AMSU and IMD dataset, have been observed. From tables 4 and 5 , the marginal variation in the position of cyclone is $0.2-0.3^{\circ}$. Figure 14 shows the comparative observation between SAPHIR and IR of very severe cyclonic storm Vardah, where on 10 December 2016, the curved band pattern increased to reach the intensity from T-3.5 to T-4 on 11
December 2016. Table 6 shows the error estimation analysis where the estimated date, estimated latitude and estimated longitude are based on the SAPHIR dataset and compared with observed data, observed latitude and observed longitude that are based on IMD best track dataset. In the mean error analysis, the positive values show that the observed cyclone position is moving forward from the best track data and vice versa.

\section{Conclusion}

In this study, we have considered the TC formed over the ARB and BOB basins of NIO during the period 2011-2018. The genesis of the cyclone genesis and the peak intensity it attained are studied using the brightness temperature as a parameter in all the six channels of SAPHIR. In all the 25 cyclones considered for this study, it is observed that landfall and/or dissipation occurred within a period of about $144 \mathrm{~h}$ (tables 1 and 2) except for the cyclones such as Mekunu, Ockhi, Vardah, Chapala, Madi and Thane which persisted for a longer period and made landfall after or near $172 \mathrm{~h}$. The observations of TC life cycle with special reference to the eye of the cyclone intensity standard fixed using the IMD and Dvorak techniques have been compared with the SAPHIR dataset. At any point of observation, the intensity variation depends upon the initial intensity of the eye of the cyclone and intensity changes in the previous $12 \mathrm{~h}$. In the next stage, we have discussed and observed the tracking of a cyclone by considering latitude and longitude positions as predictor and predictant using multiple linear regression models. The qualitative and graphical representations of tracking the life cycle of all 25 TCs have been observed from genesis to dissipation, showing reasonably acceptable positive results.

A qualitative comparison of brightness temperature of SAPHIR from all the six channels demonstrates that channel 6 is observed to be appropriate for the location of TC because the observations of channel 6 are very near to the Earth's surface than other channels and its intensity variations. More quantitative work is needed to validate this observation. The cyclone positions obtained from the multiple linear regression method are compared with the positions available from IMD information and AMSU sounder to shows marginal variations i.e., within $0.2-0.3^{\circ}$. This study can be efficiently used for tracking cyclones. 


\section{Acknowledgements}

The authors would like to express their sincere gratitude to the Indian Space Research Organisation (ISRO) MOSDAC for providing the SAPHIR sensor dataset and ICARE France. The authors acknowledge the necessary infrastructure and supporting facility provided by Jain University, Bangalore.

\section{References}

Aguttes J P, Schrive J, Goldstein C, Rouzé M and Raju G 2000 Megha-Tropiques a satellite for studying the water cycle and energy exchanges in the tropiques; Proc. Int. Geosci. Remote SE 7 3042-3044.

Balaji C, Krishnamoorthy C and Chandrasekar R 2014 On the possibility of retrieving near-surface rain-rate from the microwave sounder SAPHIR of the Megha-Tropiques mission; Curr. Sci. 106(4) 587-593.

Demuth J L, DeMaria M, Knaff J A and Vonder Haar T H 2004 Evaluation of advanced microwave sounding unit tropical-cyclone intensity and size estimation algorithms; J. Appl. Meteorol. Clim. 23(2) 282-296.

Karouche N and Raju G 2013 Megha-Tropiques level 1 products definition; Ed. 3, Ref.: TRO-0-ST-1610-CNES, pp. $1-67$.

Kotal S D and Bhattacharya S K 2013 Tropical cyclone genesis potential parameter (GPP) and its application over North Indian Sea; Mausam 64(1) 149-170.

Maneesha S and Manasa Ranjan B 2015 Impact of SST on tropical cyclones in North Indian Ocean; In: 8th International conference on Asian and Pacific Coasts (APAC 2015), Procedia Eng. $1161072-1077$.

Moore R K and Jones W L 2004 Satellite scatterometer wind vector measurements - The legacy of the seasat satellite scatterometer; IEEE Geosci. Remote Sens. Newslett. 321 $18-36$.

Corresponding editor: A K SAHAI
Nishimura S, Kato K, Mouri K, Saitoh S, Yoshida S, Endov T, Ootubo K, Shimizu A and Oyama R 2008 Analysis of tropical cyclones using microwave satellite imagery; Technical Review, No. 10, JMA, pp. 30-70.

Olander T L and Velden C S 2007 The advanced Dvorak technique: Continued development of an objective scheme to estimate tropical cyclone intensity using geostationary infrared satellite imagery; Wea. Forecast $\mathbf{2 2 ( 2 )}$ 287-298.

Raju G 2012 Megha-Tropiques mission overview; Signatures, Newsletter of the ISRS-AC 24(3) 15-23.

Roy Bhowmik S K 2003 An evaluation of cyclone genesis parameter over Bay of Bengal using model analysis; Mausam 54(2) 351-358.

RSMC Bulletin 2015 Regional Specialized Meteorological Centre, Tropical and Indian Meteorological Department Bulletin.

Sivira R G, Brogniez H, Mallet C and Oussar Y 2015 A layeraveraged relative humidity profile retrieval for microwave observations: Design and results for the Megha-Tropiques payload; Atmos. Meas. Tech. 8 1055-1071.

Suresh Raju C, Antony T, Mathew N, Uma K N and Krishnamoorthy K 2013 MT-MADRAS brightness temperature analysis for terrain characterization and land surface microwave emissivity estimation; Curr. Sci. 104(12) 1643-1649.

Ulaby F T, Moore R K and Fung A K 1986 Microwave remote sensing: Active and passive; Vol. 3, Artech House Publishers, Norwood.

Vasudha M P and Raju G 2017 Observation of cyclone occurred in Arabian Sea and Bay of Bengal from SAPHIR sensor data; Int. J. Appl. Eng. Res. 12(22) 12821-12832.

Vasudha M P and Raju G 2018 Monitoring of tropical cyclone formation, growth and dissipation by using SAPHIR sensor; Mausam 69(2) 209-218.

Velden C, Harper B, Wells F, John L, Li B, Zehr R, Olander T L, Mayfield M, Guard C, Lander M, Edson R, Avila L, Burton A, Turk M, Kikuchi A, Christian A, Caroff P and Paul M 2006 The Dvorak tropical cyclone intensity estimation technique; Bull. Am. Meteorol. Soc. 1195-1210. www.mosdac.gov.in and www.icare.fr 